\title{
The Nature of the Human Brain and a Study of Its Parts
}

\author{
Tumanako William Hongi Pugh* \\ Mental Health Community Leader, Australia
}

Submission: January 19, 2018; Published: February 02, 2018

*Corresponding author: Tumanako William Hongi Pugh, Mental Health Community Leader, Australia; Email: tumanakowilliamhongipugh@live.co.uk

\section{Abstract}

The Triune mind is the oldest relative and evolutionary part of the Human Brain corresponding to the driving of the primitive instinctive, instinctual mind such as the Reptilian Brain which houses vital control centres as for breathing, swallowing and the heartbeat amongst other subconscious involuntary actions and movements of the Body and the human physical anatomy and condition thereof. It houses the Brain Stem and the Spinal Cord which was the first to evolve in Human Evolution controlling also our spinal column alignment and the bones in conjunction with the Thalamus (part of the Limbic Brain). The Triune or Reptilian brain is responsible for prompting the appetite, hunger, sex and is also responsible for such sensations as Gut Feeling sensations, an Aching Feeling and also the sense of knowing.

The Reptilian Triune Brain versus the Emotional Limbic Brain and the Higher Mind

The Triune mind in the Human Species evolved from our earliest ancestors such as Neanderthal Man and served to drive these particularly instinctual beings simply to survive against the elements and consume a food source such as fruit, berries, nuts and roots much like our closest Primate Relatives, Apes and monkeys, satisfying their appetites for sex and hunger meanwhile dwelling in such harsh environments whilst traversing the isolated foresting's or wandering places where such Neanderthal Men survived. The next evolutionary step to take place in the Human Brain Genus is the evolution of the Emotional Limbic Mind which is responsible for our emotions such as Fear and desire, the Fight or Flight Response and Memory of which evolved to serve the instinctive Reptilian Triune Mind in times of need.

The Limbic Emotional Mind within the Human Gene Pool is also responsible for the emotions such as Attachment, Emotive and Associative Feelings, Compassion, Rationality, Reasoning, Emotional Responses, Self-Persecution and the Continuation of the Species such as Self- Procreation. The Limbic Mind evolved due to the need for small groups of Hunter-Gatherers to herd together and survive against the elements in order to sustain the group for as long as they could by acquiring a taste for meat therefore building brain tissue with a valuable source of protein, hunting for food, engaging in painting, dance and social activities such as rock painting, hand painting and finger painting, corroborees, sex and gender based activities such as child birthing, women's business, story-telling, male rites of passage and warrior-hood initiation rites whilst gathering tools relative to hunting and furthermore the procreation of the species.
The Hunter-Gatherers bloodlines can be reflected and shown through the Indigenous Aboriginal First National Native Australians in regards to their relative tool sets such as stone artefacts, living arrangements such as gender separation and daily activities such as dance, hand, finger and rock painting, story-telling, male rites and initiation rites whilst traversing the continent in nomadic clusters of tribes before colonisation by Europeans. The difference between the Triune Brain and the Limbic Mind is that the instinctive or Reptilian Triune Brain drives the Human condition to survive, such as eating and sex, whereas the Limbic Brain drives the Reptilian Brain due to the emotional responses prompted by the individual and correlated Human experiences of the individual as the desire for things such as sex, food and other emotional experiential responses. On the other hand the Higher Mind or the Neo-Cortex is the most modern portion of the evolved Human Mind which is responsible for governing the entire Brain and allows for Free-Will and the Expression of the Creativity of the Mind and also intuitive thought, regulated behaviour and social integration.

The Higher Mind or Neo-Cortex is also responsible for things such as Remembering and the overall Long-Term Memory and Mapping the spatial environment of such things as associations with colours, places of attachments and emotional responses governed by the Limbic Brain but correlated by the Parietal Lobes amongst the Frontal lobes, Temporal Lobes and Occipital Lobes of which all of these particular Lobes are housed within the Cerebrum or otherwise the totality being the Neo- Cortex. It is also responsible for Complex Reasoning and Higher Order Thinking as well as Processing, Complex Analysis, Logic, General Knowledge, Imagination, Belief and as previously stated the 
Creativity of the Human Mind. The Higher mind evolved due to select Hunter and Gatherer Groups Banding together and forming a sophisticated and structured society with needs to provide a sustainable and reliable food source brought about by agriculture, farming and the herding of livestock, safe and soundly stable dwellings, brought about by the acquisition of toolsets necessary to build homes and substantiate dwellings and finally a system of governance of Law and Government such as religion with its governing Laws, a King or Chief and/or Tribal Council and such systems of governance.

Of which is notably significant to the ancient peoples of Samaria and brought about through agriculture as the means for such select groups to band together and form a sophisticated society thereby raising the level of available brain tissue to add to the already ever-present Limbic and Triune Brain Tissue over time in acquiring tools, skills, knowledge and understandings' of the Heavens, Lunar Cycles, Harvesting, Seasons, Building techniques and Animal Husbandry methods therefore increasing human resilience to thereby survive in numbers. And so by then increasing neuroplasticity by such an evolutionary step towards acquiring a neo-cortex and the continuation of the Human species in providing stable and safe dwellings such as mud huts, a reliable food source such as crops, a valuable and reliable meat source such as livestock and cattle, safety in numbers such as a rudimentary form of Government such as a King or a Chief(to rule, protect and govern) and finally a system of governance of Law such as religion and the structure of a religious elect to provide spiritual guidance to the King or Chief and the people as a whole.

The difference between the Higher Mind or Neo-Cortex and the Reptilian Triune Mind and also including the Limbic Emotional Mind is that the Neo-Cortex allows for Free-will which is not available to both the Limbic mind and the Triune Mind which simply provide for the survival and procreation of the species therefore being driven by the emotional responses and experiential experiences of such instinctive drives to sustain themselves without Free-Will for as long as possible in order to survive, herd together and procreate the species thereby placing their individual and collective footprints in resonance to the creation of the next evolutionary step of acquiring a neo-cortex. In summary the instinctive Triune Reptilian Brain is the driving force of the Human Mind whereas the Emotional Limbic Brain serves the Reptilian Brain in satisfying the needs of the Triune brain such as sex and hunger amongst other servicing of needs such as the regulation of hormones and processes therefore the Higher Mind is the processing unit governing the Human Mind and therefore condition which gives for Free-Willed Higher Order Thinking and processing.

By correlating such individual Human experiences contained within the memory ordered by the Higher Mind and driven by the Emotional Limbic Brain and otherwise the intrinsic Triune brain thereby reasoning through Logic and Intuition, of the higher neo-cortex, to guide the Emotional Limbic and Triune Brain entirely as a sending and receiving information processor due to the experiential experiences of the Human Mind.

To bring to bear a brain that processes information based upon its intrinsic nature of being driven by its core instincts, governed by its experiences and emotions and how we ourselves view ourselves in society(generated by such experiences) and thereby correlating them logically, rationally and reasonably by utilising the higher intuitive mind to make appropriate or otherwise inappropriate decisions governed by one of experience and the decisions made by the modern day man and the behavioural traits thereof.

\section{An anatomical study of the Human Brain and its parts}

The Brain is made up of Grey Matter and White Matter where Grey Matter is involved in analysing information meanwhile White Matter conducts information between Grey Areas [1]. The Human Brain is made up of 4 parts being the Cerebrum, the Cerebellum, the Limbic System or Emotional Brain and finally the Brain Stem or Reptilian Brain [2] (Figure 1). The Cerebrum (shown above) is the earliest evolutionary portion of the Human Brain, in the above diagram the nature of the right and left hemispheres of the higher mind or Neo-Cortex is responsible for controlling the left and right side of the body such as that the left hemisphere of the brain or left hemisphere of the Neo-Cortex and controls the right hand side of the body, logic, rationality and reasoning whereas the right hemisphere of the brain or right hemispheres of the Neo-Cortex controls the left hand side of the body, belief, creativity, imagination and the higher intuitive functions of the brain [3]. The 2 Hemispheres in Longitudinal Relationship are made up of bundles of nerve fibres called Corpus callosum which binds left and right Hemispheres and allows the left side of the Brain talk to the right and so forth back again therefore communicating with the left and right associated longitudinal Brain Structure of the Human Psyche.

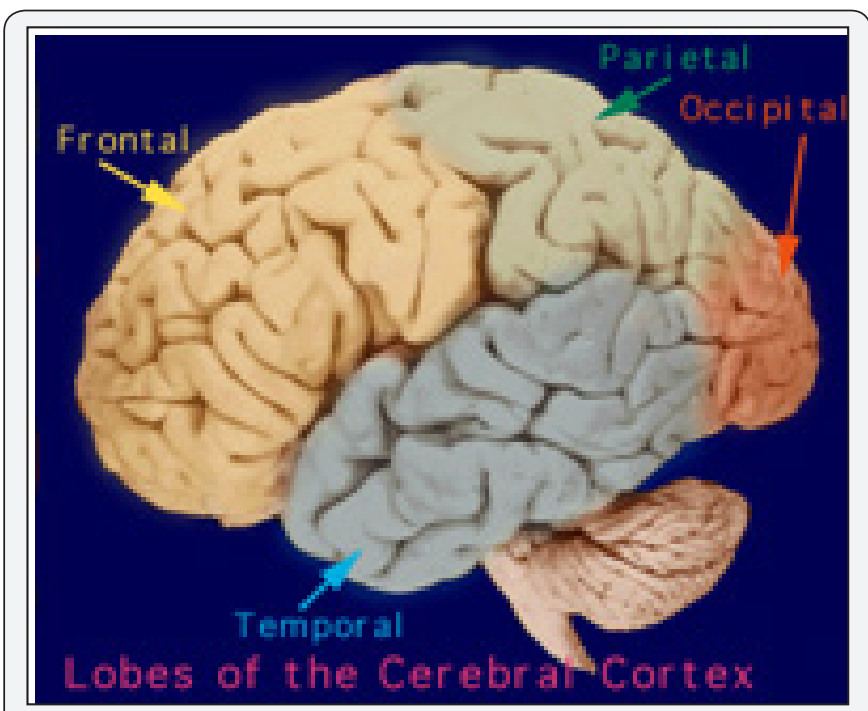

Figure 1 : Model of Cerebrum and its' corresponding parts. 
The Neo-Cortex or Cerebrum is made up of 4 major parts such as the Frontal Lobe, the Parietal Lobe, the Temporal and Occipital Lobes [1]. The Frontal Lobe lies at the front of the cerebrum just behind the forehead and under the Frontal Skull Bones. The Frontal Lobe is responsible for coordinating voluntary movements, assessing future consequences for current actions, assessing similarities and differences for two different objects, formation and retention of long-term memories (particularly emotional memories derived from the Limbic Brain) Language, emotional expression and regulation, personality development, reward management and finally attention regulation including selective attention [4].

The Occipital Lobe on the other hand is mostly unknown in regards to its full functions though can be shown in mapping MRI Scans to be placed on a thin membrane between the Cerebrum and the Cerebellum and predominantly been discovered to be responsible for such things as visual memory, colour association such as colour determination in a visual field, assessing distance, size and depth, transmitting visual information by encoding memories, assigning meaning, craft appropriate and linguistic motor responses, continuation of responding to information from the outside world and finally receiving raw visual data from the eye's retina [4]. Not entirely a lot is holistically known about the Occipital Lobe and it is suggested that such functions may be wider than previously inclined.

The Temporal Lobe lies at the base of the centre of the Cortex, just behind the Temples and is responsible for the formation of visual memories in relationship with the Hippocampus, Cerebellum or Thalamus, Hypothalamus and the Amygdala including long term memories, the assignment of meaning amongst other such regions such as the Ventral Lobe housed within the Temporal Lobe which allows us to read body language and recognize faces, the production of speech and speech development, recognizing languages, controlling appetite, thirst and hunger and finally controlling Homeostasis [4]. Furthermore the Parietal Lobe lies above the Occipital and Temporal Lobes and behind the Frontal Lobe of which this Lobe is separated by Parietal-Occipital Sulcus from the Frontal lobe meanwhile Lateral Sulcus separates the Parietal Lobe from the Temporal and Occipital Lobes. The Hemispheres of such a Lobe is divided by such a thin membrane in a Medial longitudinally associated manner [4].

The Parietal Lobe is responsible for spatial orientation, visual-spatial orientation and Reasoning, distinguishing between two points even without visual representation, also localizing touch, integrating sensory information from most regions of the body, visual functions in conjunction with the occipital lobe, assessing numerical relationships and number of objects viewed, assessing size, shape and orientation in space, co-ordinating hand and eye movements, processing language and coordinating attention and finally mapping the visual world [5]. These are the corresponding parts of the Cerebrum or NeoCortex and its human behavioural and functioning responsibility it serves and resulting actions and experiential learning able to resiliently resound regarding the nature of the Brain and its present parts.

\section{The Limbic System}

The Diencephalon is made up of the Hypothalamus, Thalamus, Sub thalamus and the Epithalamiums. The Thalamus is housed as a part of the Limbic Brain connecting the Cerebrum to the Mid Brain (part of the Spinal Column) and is responsible primarily for balance, orientation and the aligning of the Spinal Colum in relaying information to the Neo-Cortex or the Cerebrum for associations and memory storage, relating information as having meaning, also experience as being meaningful and determining memory allocation [6] (Figure 2).

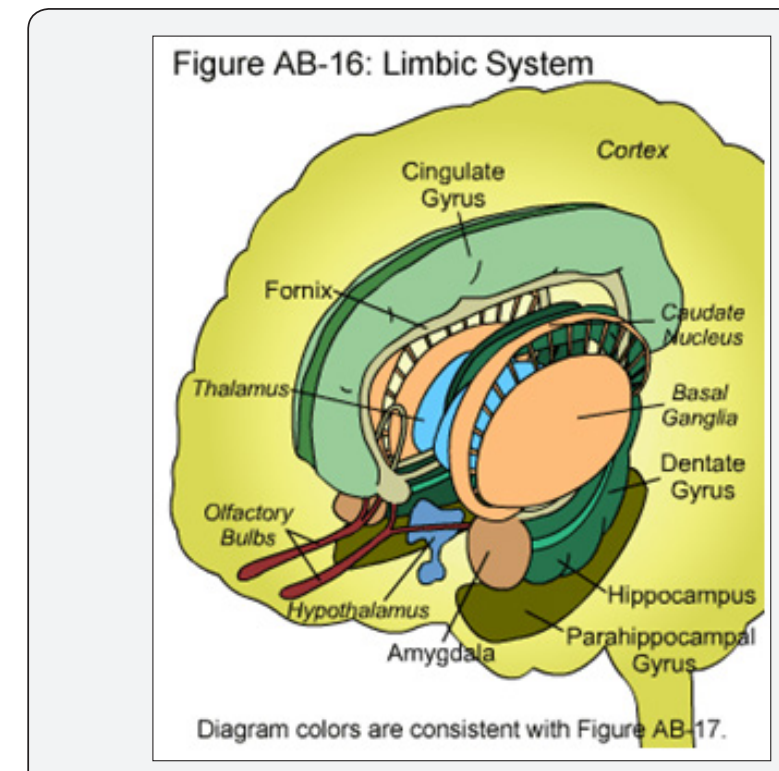

Figure 2 : Model of the Limbic Emotional Brain and the System thereof.

Within the central interior tissue of the vermis rises a white stem known as Abor Vitae [7]. The Hypothalamus is also part of the Limbic Brain, beneath the Neo-Cortex and above the Reptilian Spinal Cord and Brain Stem and beneath the Thalamus, which is also part of the Limbic Brain of which is responsible for linking the Nervous System with the Endocrine System via the Pituitary Gland (hypophysis) and is predominantly responsible for regulating the metabolic processes and other activities of the Autonomic Nervous System, it synthesizes and secretes neurohormones often called hypothalamic releasing hormones [8].

\section{The Pituitary Gland}

The Pituitary Gland is often called the master gland as it controls several other hormonal glands in the Human Body including the Thyroid and Adrenals as well as the Ovaries and Testicles. It secretes hormones from both the front part (anterior) and the back part (posterior) of the gland [9]. If the Pituitary Gland is not producing sufficient amounts of one or more hormones this is called hypopituitarism meanwhile on the 
other hand if you are over producing certain hormones, then you would have features due to the over production of the specific hormone concerned [9] (Figure 3).

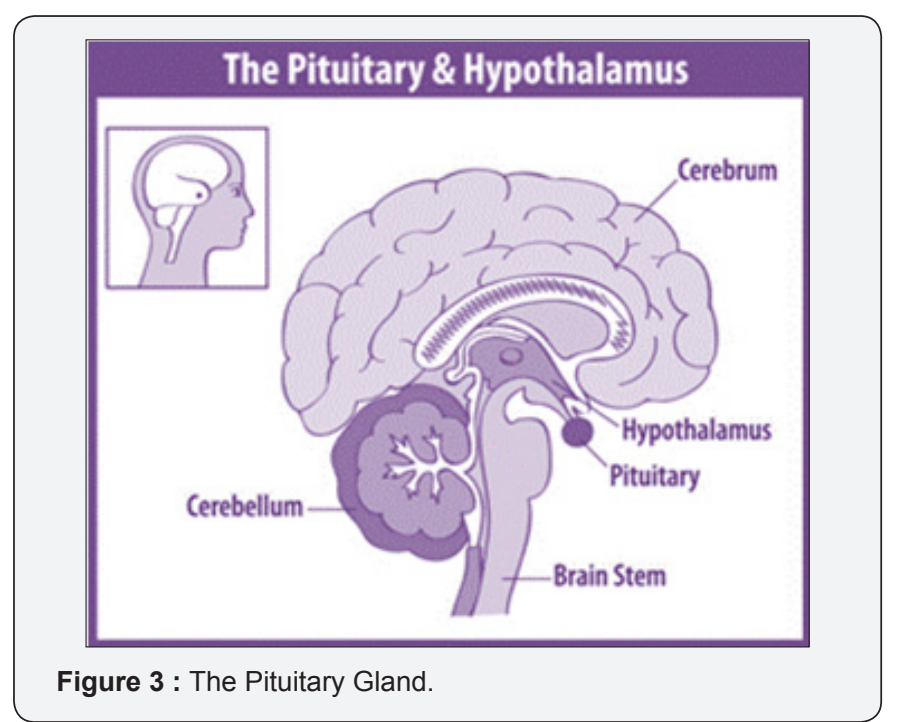

\section{The Epithalamus}

The epithalamus consists primarily of the Pineal Gland and the Habenulae. The pineal gland is an endocrine gland that secretes the hormone melatonin, which is thought to play an important role in the regulation of circadian rhythms [6] (Figure 4).

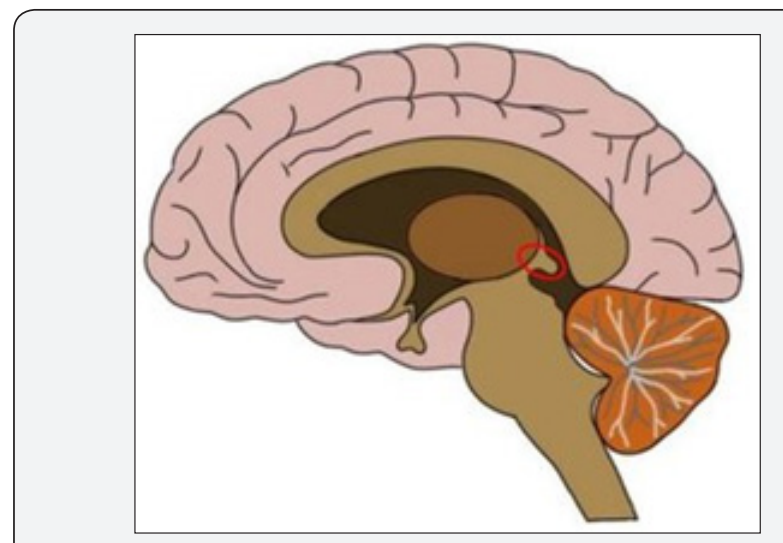

Figure 4 : The Epithalamus.

\section{The Pineal Gland}

The pineal gland (also called the pineal body, epiphysis cerebri, epiphysis or the «third eye») is a small endocrine gland. It produces melatonin, a hormone that affects the modulation of wake/sleep patterns and photoperiodic (seasonal) functions. It is located near to the centre of the brain between the two hemispheres, tucked in a groove where the two rounded thalamic bodies join. Unlike much of the rest of the brain, the pineal gland is not isolated from the body by the blood-brain barrier system. It is reddish-grey and about the size of a pea (8 $\mathrm{mm}$ in humans) [10] (Figure 5). While the physiological function of the pineal gland has been mostly unknown until recent times, mystical traditions and esoteric schools have long known this area in the middle of the brain to be the connecting link between the physical and spiritual worlds and are considered the most powerful and highest source of ethereal energy available to humans.

The pineal gland has always been important in initiating supernatural powers. Development of psychic talents has been closely associated with this organ of higher vision. The third eye controls the various bio-rhythms of the body. It works in harmony with the hypothalamus gland which directs the body's thirst, hunger, sexual desire and the biological clock that determines our aging process. When it «awakens», one feels a pressure at the base of the brain. The pineal gland's location deep in the brain seems to intimate hidden importance. In the days before its function as a physical eye that could see beyond space-time was discovered, it was considered a mystery linked to superstition and mysticism. Today it is associated with the sixth chakra [10]. As shown by the figure below, the placement of the Pineal Gland in the Brain is as outlined in Figure 5.

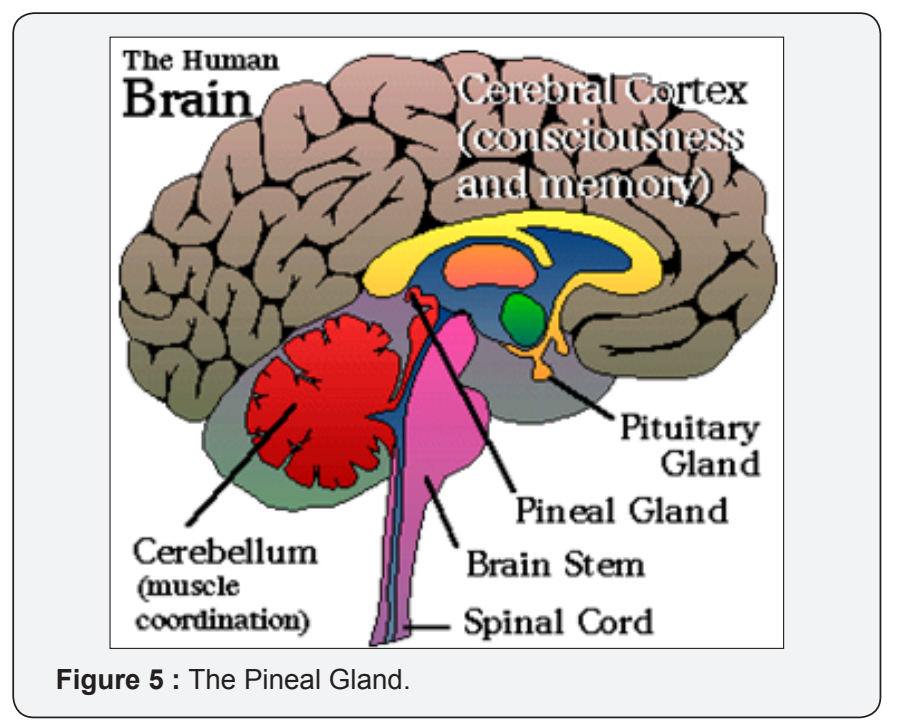

\section{The Habenulae}

The Habenulae (more often referred to with the singular: habenula) are two small areas near the pineal gland. The functions of the Habenula are poorly understood, but it is thought to potentially be involved with reward processing and has been implicated in depression. Additionally, there is evidence that the habenula also produces melatonin, and that it might be involved with sleep regulation [6]. This particular region of the brain is responsible for temperature regulation, thirst, hunger, sleep, mood, sex drive and the release of other hormones as outlined previously [6].

\section{The Hippocampus}

Whereas the Hippocampus is also housed within the Limbic Region of the Brain controlling mainly such functions as memory, emotions and motivation and is located in the Medial Temporal Lobe [11] (Figure 6). 


\section{Psychology and Behavioral Science International Journal}

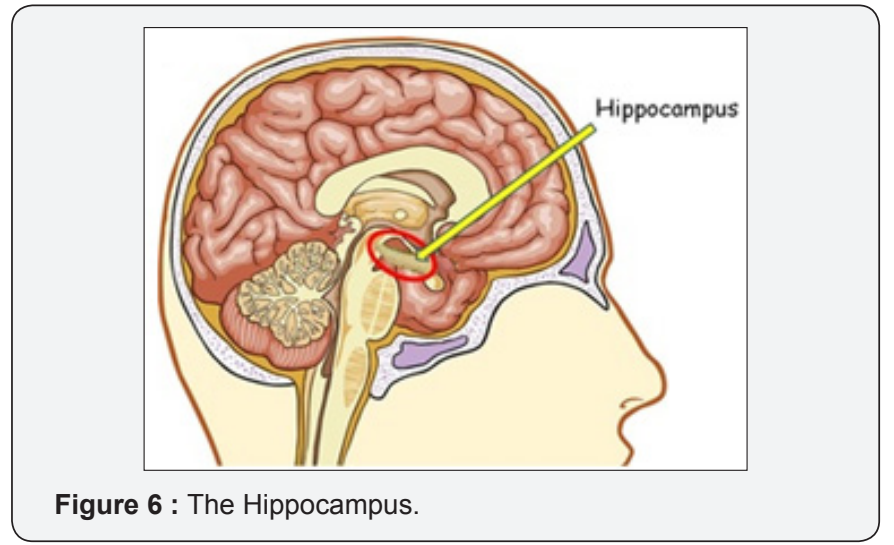

The Amygdala

On the other hand the Amygdala is responsible for processing memories, decision making and emotional reactions and sends such information to the Neo-Cortex [12] (Figure 7).

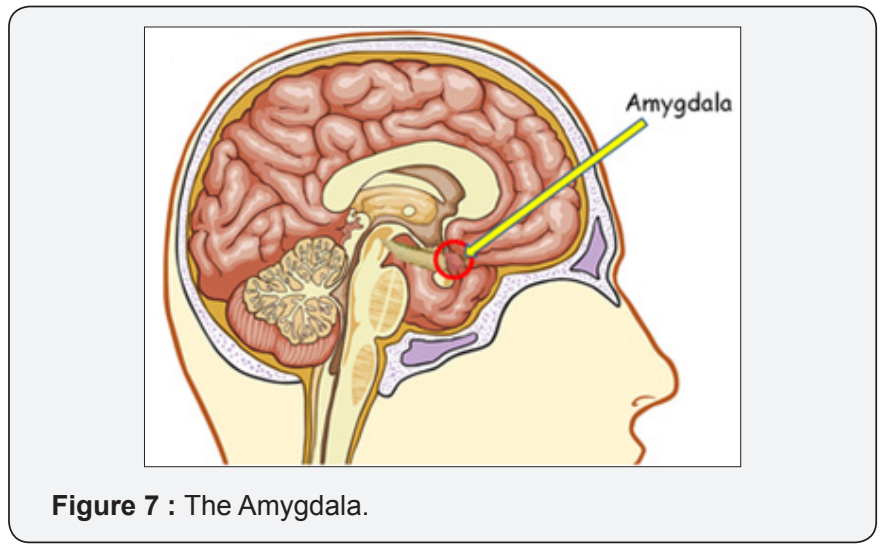

The Cingulate Gyrus

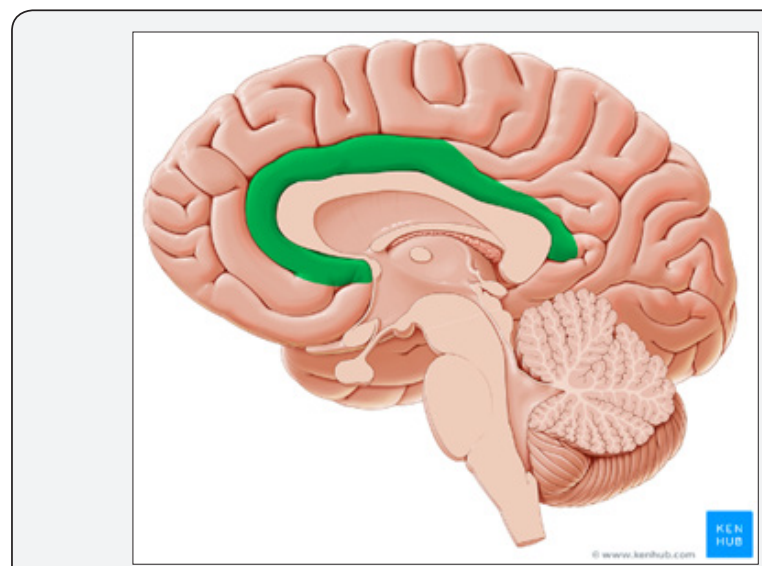

Figure 8 : The Cingulate Gyrus.

The Cingulate Gyrus on the other hand serves as a pathway that transmits messages between the inner and outer parts of the Limbic System [13]. The functions of the Cingulate Gyrus are coordinating sensory input with emotions, emotional responses to pain, the regulation of aggressive behaviour, communication, maternal bonding, language expression and decision making
(Figure 8). And in total resonance depicting the Emotional Limbic Brain is regarding parts of the Limbic Brain entirely (Figure 9).

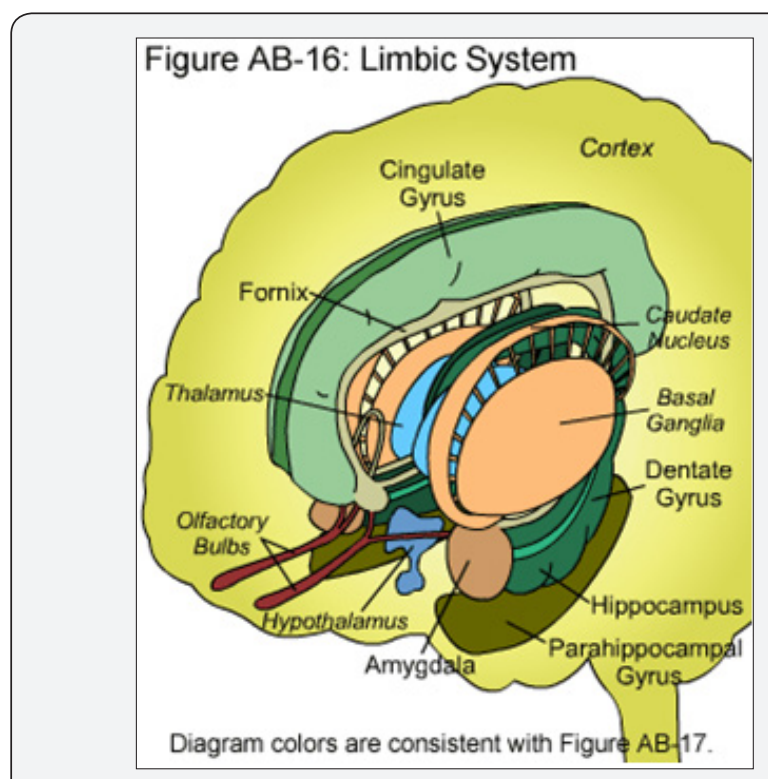

Figure 8 : The Cingulate Gyrus.

\section{The Cerebellum}

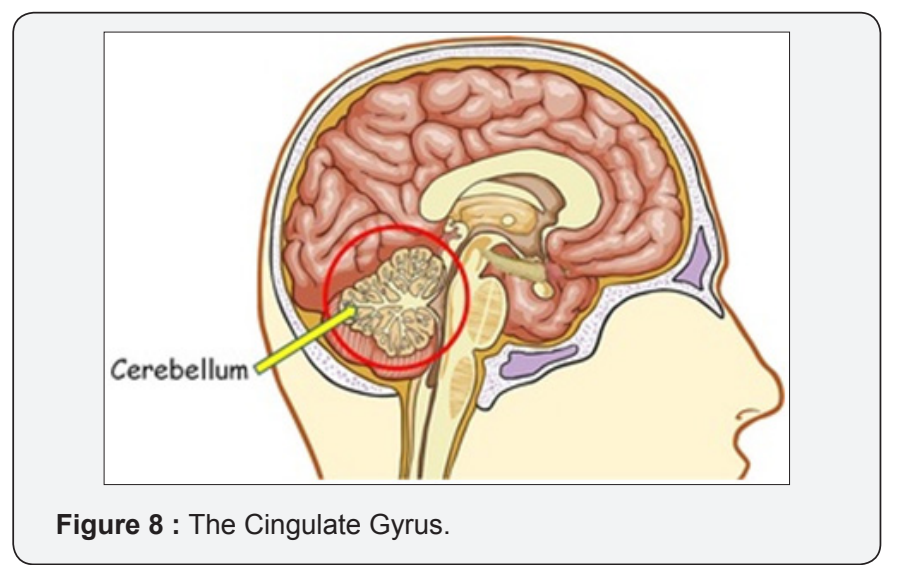

As a Counterweight the Cerebellum is said to be much older than the Cerebrum as reptiles on an earlier evolutionary scale have a fully developed Cerebellum meanwhile is associated and medially aligned in Hemispheres alike the Neo-Cortex and such associations [2]. The Cerebellum just like the Neo-Cortex is halved into Hemispheres in left and right associations as previously mentioned and are connected by Vermis fibre tissues, connecting the Cerebellum to the Neo-Cortex or Cerebrum and the Brain Stem, Spinal Cord and Diencephalon [14] (Figure 10). The Cerebellum is responsible primarily for the voluntary movements of the body relating to spatial orientation and also other things such as memory, hence the Limbic Brain, and also the release of hormones, sex drive, mood, sleep, hunger and thirst including temperature regulation [14]. The Cerebellum is closely related to the Limbic System and as such the Limbic System houses the Thalamus, the Hypothalamus, the Hippocampus, the Amygdala and other Glands responsible for sending and 
receiving information from the Thalamus and sending such encoded information to the Occipital Lobe and Higher Mind, Neo-Cortex and/or Cerebrum [14].

\section{The Reptilian Triune System}

And finally in conclusion the Brain Stem connects the Spinal Cord to the Higher Order Thinking Centres of the Brain. It consists of 3 major structures the Medulla Oblongata, the Pons and the Midbrain. The Medulla Oblongata is continuous and connects to the Pons above whereas the Medulla Oblongata and Pons are considered to be part of the Hindbrain whilst the Midbrain or Mesencephalon connects the Pons to the Diencephalon or Thalamus and the Forebrain [2] (Figure 11). And as previously mentioned the Brain Stem or Reptilian Brain controls involuntary movements and regulates such things as breathing and such other involuntary actions. The Reptilian Triune Brain is the oldest relative portion of the Human Brain and drives the instinctive needs to survive, such as eating, procreate with other Humans during sexual intercourse or otherwise the continuation of its own self-procreation.

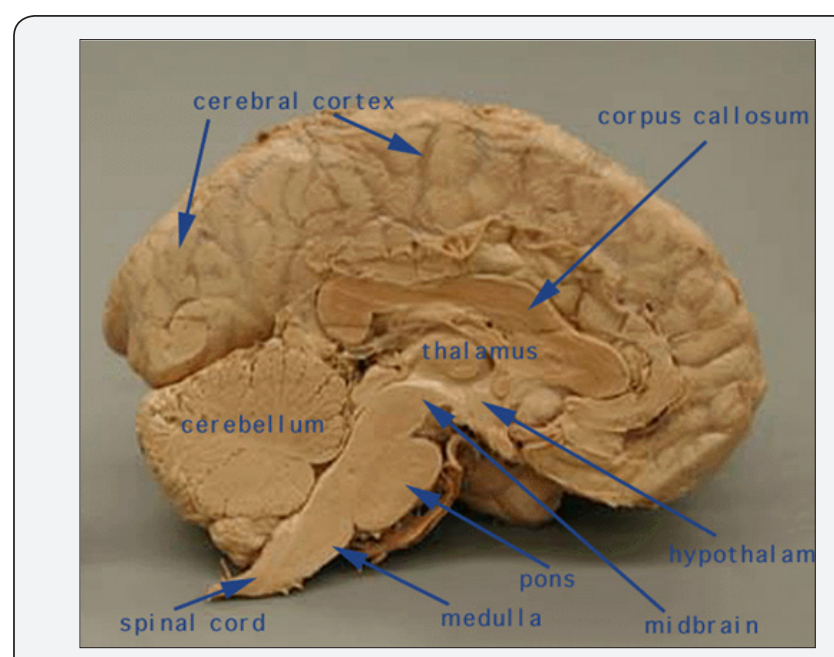

Figure 11 : Model of the Brain Stem and its' relative parts.

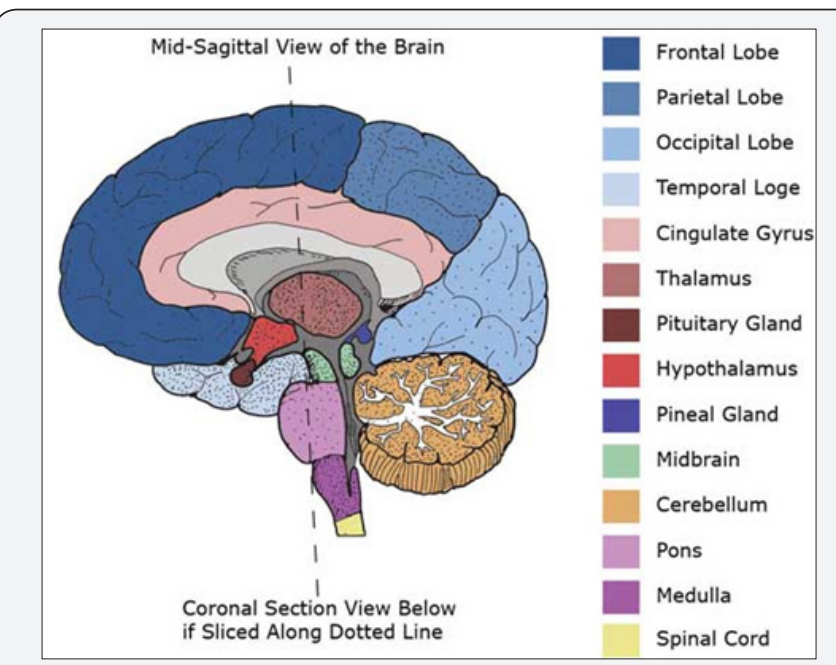

Figure 12 : Overview Model of the Human Brain and its' relevant corresponding parts.
The Reptilian Brain not only drives the instincts but also serves the instinctual needs to survive and compete for ground by governing the mind by its instinctual drives and needs it services (Figures 12 \& 13). The Reptilian Triune Brain is important in that it controls involuntary movements such as the heart and other involuntary processes such as breathing, swallowing and the movements of the heartbeat as previously mentioned.

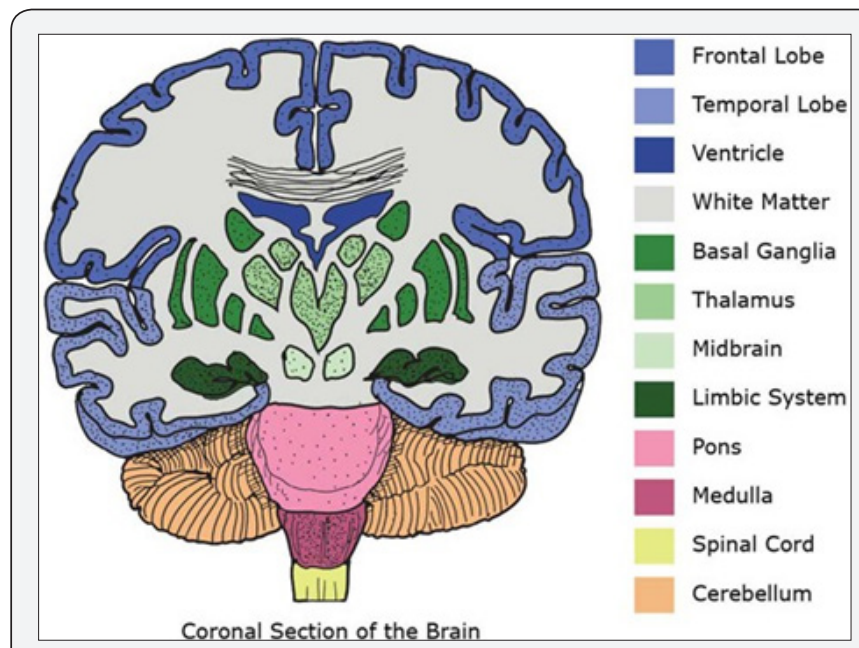

Figure 13 : Overview Model of the Human Brain and its' relevant corresponding parts.

A Psychological Viewpoint of the Principles regarding Masculinity, Femininity and the Unification of the Psyches and Archetypal Principalities

In regards to the Principles relating to male and female roles and principles in society arguably so there is a need to align the major influences of such masculine and feminine principles within the Psyche as societal pressures of a sophistication of society and the individual individuation of society persists. Showing that such an imbalance between these major principles in the Collective Consciousness such as contained within the Human Psyches is responsible for such things as inadequicies, insecurities, imbalance and the domination of societal issues being portrayed in soceity, such as, neglecting such a balancing of masculine and feminine principles within male and female roles and the collective consciousness.

Of which is denying Humanity the full extent of Human Lifetime experiences to be expressed as Aging Gracefully in oneness balanced in the Pysche regarding the Human Brain, wholeness in the unification of Masculine and Feminine Principles outlined herein, the absoluteness of an Infinite Spark of Infinite Potential contained and expressed by the Intuitive Mind or Higher Mind. And furthermore completeness of Human Resilience governed and managed from a position of Overall Wellbeing, Health, Mental Health and Wellness therefore moving from a position of Hopelessness to one of Hope, Commonality in Sharing our Stories of Recovery, Balanced Archetypal Principalities, Gender Role Personality Traits regarding Masculinity and Femininity as one, Non-Dualism neither isolating either in True Neutrality. 


\section{Psychology and Behavioral Science International Journal}

Thereby governing the Principles, Archetypes, Associations and Assumptions of the Modern Day Man ever-evolving in Quantum Mechanisms of its component parts. Then so such inadequicices, insecurities and imbalance of Male and Female Principles within the Psyches results in acting out in a brutal male dominant manner or otherwise fear minded mentality of a female dominant Psyche regarding each our own individual gender roles. And the inability for such individuals or otherwise most Human Beings to be in a state of harmony and balance meanwhile acting out such an imbalance by portraying a predominantly Masculine role or otherwise predominant Feminine role of which is to neglect that we all, male and female have a collective consciousness and that it is to be balanced Masculine with Feminine or otherwise Social Principles of Master, Servant, Pauper, Richness, Slave, King or Queen in balance with itself King or Queen in its role association and harmonious traits being as one.

In that the Planet and Humanity is in a State of Emergency regarding overall Wellbeing, Health, Mental Health and Wellness of the Global Environment and Collective Consciousness of Mankind and the entire Earth. And furthermore balancing such Archetypes as Godman or Godwoman with follower/Devotee just as importantly as other Archetypal principles relating to such Religious Sects or Religious Institutions such as being institutions of God or the Devil being reflected upon the Psyches in a unified manner of balance between light and dark principles regarding itself or the collective consciousness and sub-consciousness. Meanwhile not primarily being as one and the same altogether but from a unified perspective always in reflection and balancing polarities between light and dark entities within the collective consciousness of the collective pyches as one.

Balancing such dark and light polarities of associations of the mental reflections between the conscious and sub-conscious minds and living in harmony in a non-dualistic state of existence with such associations or on the other hand societal roles that we each 'take up' as individual roles and pursue each in our own way, means or ability one unto another in society to do so accordingly and appropriately in a unified balanced Non-Dualistic state of Mind, Body, Soul, Spirit, Socio-Economy, Balanced Masculine and Feminine Principles, Health, Mental Health, Arighted, Unified and Well-balanced Archetypal Associations and Archetypal Assumptions. Whilst remaining Mindful and Valuing each our own Overall and Collective Wellbeing holistically entangled in Quantum Mechanics in that we as one, all Doctors, Psychologists, Psychiatrists, Neuroscientists and Neurologists, Mental Health Proffessionals and/or Mental Health Workers are Quantum Mechanics regarding Human Recovery and the Quantum Entanglement of the Human Behavioural Sciences, Collective Psyches and Collective Consiousness of the Earth.

In that Conceptualised Quantum Mechinics is the Distribution of Values regarding the Product Multiplication Beginning Point or otherwise Subsequent Divison or Dividing Beginning Point through Division and entangling it through Multiplcation entirely as an entanglement of its Component parts and then so the resulting product of Component Parts Quantum in its Whole entirety is then brought to its solution by its further Divisive Dividing Division of all parts therein, contained therein, in superposition, up or down. Therefore utilising as to whether the equation begins with Division or Products will Determine firstly as bringing it to solution and resolving the equation in Mechanised Solution and then it will be so in turning to its positive or negative Parts appropriately and accordingly so as so, not simply just to 'pearl' all pearls on a string individually expanding AD INFINITUM.

But to utilise the method of starting on either positive products and resolving through negative division and so forth back to the entire complementary part being fully entangled as a product and therefore bringing a Value to its own Product entanglement to be then in further Division entirely as a Super-imposed Fractal Super-imposed and Reflecting on itself in Division again. And as to where an equation begins and regards itself as a Product or Quotient and so furthermore will be determined by as to whether it be in Division or Product Rules initiatlly and applying the next step as an initiation of Mathemathical Resolutions and so applying such as the Quotient and Product Laws of Quantum Architecture is a Rule of a Law of Mathematical Functioning Systems of Resolution 'Rule of Thumb'.

Of which is possible through its positive product or negative division origin's in regards to as whether either Division or Multiplication Functioning Laws are applicable in the functioning system equations resolution and how Quantum Mechanics should be regarded and applied. And applying such Rules appropriately and so from its beginning origins of as to whether Beginning in Division or Beginning as Products and so forth therefore from there all can be seen. At all times either expanding through entanglement and then division or beginning in division then to one of expansion in a continual Geomitrical Equational Sequential Scientific Processing and Reasoning and furthermore a Geometrical Progression of Quantum Mechanics $\mathrm{AD}$ INFINITUM and through-out the nature of Neuro-Science entirely as Quantum Machinery.

Then so as being that all Doctors, Health Professionals, Mental Health Professionals, Physicians, Clinicians, Human Beahavioural Scientists and Specialists, Anatomical Specialists, Surgeons, Nurses, Wellness Officers and Wellness Personal Assistants, Peer Support Representatives including Peer Support Ambassadors, Role-Models, Advocates and Community Organisations, Psychologists, Psychiatrists, Neurologists and Neuro-Scientists are Quantum Mechanics Regarding the Wellbeing of the Client, Victim, Patient and the Servicing of Needs to the Individual entirely as a Service Provider servicing the entirety of Humanity. Utilising Scienftific Processing and Scientific Reasoning through Methodology of Self-Experimentation as always ever-evolving through one of Logic and Intuition of the Component Mechanics of its corresponding parts as being brought unto alignment and the furthermore subsequent resolution of its delineating by- 
products being stable and always relfecting on itself whether in superpositional Divide or Quantum Entanglement of Product Resolution neither being isolated from the other.

And the solution presented to the Self-Experimentation Process being Given and Presented and Expressed in another System of Methodology and Refinement of each our own Self-Experimentation Processes again. Thereby reflecting upon ourselves and giving Clients, Patients, Victims, Users, Participants, Community Members and Consumers, the Tools and Toolkits, Skills and Skillsets, Knowledge and Wisdom, Guidance and Understanding, Gentleness and Patience, Couselling and Comfort, Support and Non-Judgement, a Listening Ear and Always Mindful, meanwhile Providing Hopeful and Full of Hope Engagements, whilst holding Eye and Facial Expression Contact through Connecting with the eyes, Unconditionally Loving Treatments, Giving Advice and Treating an individual as a complete person regarding their needs at the instant of presentation into care.

And so only upon stringent rules shall such discharging of patient be rendered and taken away from Individuals and meeting all Clients at their most despairing and what their needs are at the time of presentaion to the particular Service Provider meanwhile in gentleness being able to recognize the overall position of the issues concerning such a Victim, Client, Individual and/or Patients needs through Discernment, Observations Made, Research and Conclusive Evidence by Valuing Doctor, Patient and Client intel and Personal Privacy and Confidentiality Legislation furthermore Valuing Doctor and Patient Relationships altogether. Meanwhile also being Accepting, Full of Grace whilst Humble, Able to Judge with Better Judgements upon ourselves and NonJudgemental of others and furthermore the Bringer, Giver and Receiver of Glad Tidings therefore becoming the Harbringer of all Tidings, good or bad.

To be as ourselves Resilient, always bouncing back with ease, obtaining Human Resilience and Building Further Advancements in the field of Science, Medicine and Human Behaviour as one and Reflecting upon ourselves and towards others in regards to entirely being Role-Models of Examplary Behaviour and Highest Esteem, Community Minded, Health Orientated Professionals, Mindful and Grateful individuals of Much Substance and Invaluable Worth regarding the Pricelessness and Worthiness that a Doctor or Service Provider holds knowing such a value we put into the Worlds' Health and Well-being therefore unifying the Earth and Humanity by a Viewpoint of Overall Well-being.

To balance the Collective Consciousness holistically not just as Mind, Body, Soul and Spirit as one unified but also as the roles we each individually undertake in society to bring a wholeness to those that we as Doctors of Medicine with inclusivity regarding Psychologists and Psychiatrists of which we reflect a unified Overall Wellbeing and Wellness of being regarded as not suffering from such inadequicies as not being individually impacted upon by the Mental Health Communities from the inability to express
Love or otherwise an imbalance of the Unifying collective and universal connectivity meanwhile not expressing all fears nor violence to be made manifest through the abuse of Power. And furthermore including non-begnin aspects in regards to any malalignment of Personality due to the inadequicie to Father, Sire or Bear Children or if unable to procreate due to Health reasons, and so forth, not to go about and acquire All-Wealth, All-Power or other such All God-like Beinghood of Archetypal Assumptions of Associations of such Archetypal and Religious Principles.

Therefore by balancing all component parts of the Collective Consciousness to thereby encourage the overall balancing and combined unification of the masculine and feminine principes and/or the Masculine and Feminine Minds together as one by being unconditionally loving and kind, unconditionally generous and eager to 'just laugh it off', 'dust ourselves and others off', 'shrug it off' and 'get over it entirely', 'not mentioning it ever again', only 'in joyous bouts' of laughter for others wellbeing and meanwhile being 'learned in letting go of past issues neither holding anymosity nor grudges'. Furthermore the having and holding onto Hope, the empowerment of the Arts and the value we as one put to the Creativity of the Mind, Intuition, Reasoning and Logic, Rationality and Emotinal Content in Health, Mental Health and overall Wellbeing and Wellness therefore increasing Human Resilience in our own lives and reflecting such towards others as shining lights of Hope.

That by bringing about a total alignment of Psyche such as from a Tao-istic viewpoint regarding the Yin and Yan principles in total alignment and harmony between light and dark, masculine and feminine, living in non-dualism in regards to the Collective Consciousness being in alignment and balance, to bring about harmonious lifetsyles and seeking at all times commonality or neutral ground from a position of the middle path or middle ground in unifying all principles of Archetypes and imbalance by one of neutrality to relate from one to another in commonality or equity rather than just piety nor a state of have's and havenots but from a position of Non-Dualism, Neutrality, Equity and Commonality. To bring Psychological treatments into greater alignment with such concepts and principles of Principalities or otherwise reflections of balance collectively unifying principles and Archetypes, entirely as one, neither isolating either or otherwise.

And address such societal issues regarding gender roles from a viewpoint of equity between the sexes and harmonious balance, balancing between the collective Masculine and Feminine Gender associations and principles that are at work here within the individual consciousness and collective Psyches of Humanity as unifying the individual consiousness and Sub-consciousness, Principles of Masculinity and Femininity, Archetypes and Associations. Giving value and meaning to such individual lives and Hope to continue in our lives unabated in acquiring such skills to better manage our lives and further our understanding in regards to unifying the Psyches, The Principles regarding Masculine and Feminine roles and Archetypes of religion or on 
the other hand Associations with being or regarding ourselves as one of Poorness or Richness none isolating another. Meanwhile not providing treatments in Psychology or Psychiatry relative to the need to do so as such as isolating one from another of which is a contradiction of what Psychology represents as being a total unification of Mind, Body, Soul and Spirit and the overall wellbeing of each our own Individual Health and Mental Health including the unified Health, Mental Health and Overall Wellbeing of other Individuals Globally as paramount within society Today as a whole.

This is the major argument being concieved through this work and arguably so bearing individual lives the total collective unification of connectivity in regards to Mind, Body, Soul, Spirit, Socio-Economy, Masculine and Feminine Principles including Balanced and Harmonious Archetypal Associations and furthermore our view of ourselves and others, towards treating the patient or client holistically from a positon of NonJudgement, Support Neutrality, Equity, Gentle Guidance, Empathy, Compassion and Commonality. And no longer regarding piety as a means to align humanity nor otherwise simply inacting a gender role as primarily being one of Male versus Female in a dominant Masculine role exacting means and methods of acquiring ones' desire's or otherwise Female versus Male in a predominantly Feminine Fear-Minded Mentality and the need to address such inadequicies regarding Male and Female sexuality and the individual roles each plays.

Of which are important altogether and the needs to recognize that neither male or female roles are absent of such a principle of inner and outer balance and a 6 Dimensional Shift in $\pi$ degrees of connectivity, harmony and oneness of which is the only means to effectuating such an overall Wellness, Wellbeing, Mental Health and Health Holistically. For such a paradigm shift to also reflect the need for the overall unification, connectivity and balancing of the entire Human Brain, as we now have it, to unify the Reptilian Brain with the Limbic Mind and the Higher Mind or Neo-Cortex, neither isolating either. To argue in the affirmative in regards to the normalizing of sharing individual Human experiences of a lived kind with mental illness rather than normalizing Human experience as being one of disregarding the dynamic Human Spirit and not encompassing the validity of the dynamic Human Psyches meanwhile ruling out such uniqueness and placing all things as being normal of course is an untruth.

In that each our own individual Human Footprint and Gene Pool reflects our dynamic nature and to normalize what is dynamic is to disregard the Human Spirit to overcome obstacles, rise above any challenges and meet problems head on of which is the nature of the dynamic Human Spirit to but perservere and overcome through persistence and perserverance to then become the best one can be and not let go of Hope. To encourage overall Wellbeing and Wellness with Health as Being Paramount in aligning such Brain Structures as one, whole, complete and absolute, neither one more important than the other nor isolating one from another. To bring to bear the connectivity of the entire functioning of the Nervous System and Physical Function of the Human Body entirely unified under the Principles of Overall, Wellbeing, Health, Wellness and Mental Health as one, whole, complete and absolute. In that the Human Anatomy is one to be regarded as an overall oneness and interconnectedness of unification, of all and between all corresponding parts regardless of what particular role each part Anatomically plays in the Human Body or Human Psyches. To encourage further research into the nature of the Brain and such Masculine and Feminine Principles at work herein outlined to advance understandings in the field of Psychology and Psychiatry thereby advancing Science and Medicine as one.

\section{Conclusion}

Therefore in conclusion this piece is an outline of the Human Homo-sapiens and Thinker Thinker Brain Anatomy and how we view ourselves and our perceived and conceived realities, finally our views of the Human Brain and the study of its parts relating to human behaviour and human experience governed by a sending and receiving instrument detailing through memory and spatial orientation associations and other Human experiences of the Reptilian Brain interpreted emotionally and experientially via belief, imagination and the creativity of the neo-Cortex world regarding social integration and conformity. By a governing principle that the Human Brain is a Tool of great wealth to the Human Psyches and all its parts including Wellbeing, Wellness, Health and Mental Health in correlating information as the initial impetus of all action as the consciousness controlling the driving mechanisms of the Human Consciousness. Whilst being mindful of the individual as being in the passenger seat and the mind controlling the determination of our perceived or otherwise resulting realities through our Reptilian Driving Instinct to Drive our Minds and to furthermore build human resilience entangled with the emotional Brain and Higher Order Thinking and Processing, Reasoning Mind, Logical Mind and Beliefs including Imagination, Creativity and Intuition.

So therefore in conclusion Human Resilience in regards to the already capable and functioning Modern Day Homo-sapiens and Thinker Man or Woman is to value the full nature of the Brain, bring it to full awareness of itself and finally build on an already valuable Neural-body and Neural-cellar tissue in acquisition of further neural tissue and further advance in the understandings of each our own individual and collective Human Psyches'. And all Human experiences to bring value to such individual experiences as a spatial orientation and connectivity between individual Humans and entangled 8 dimensionally up, down, left and right, front and back, in and out of $\pi$ degrees' and how we as a Species view ourselves in society and how society views us, breaking down barriers in each our own lives and being of exemplary behaviour to break down obstacles presenting themselves to other's.

By building upon a valuable tissue of Creativity, Imagination, Belief in the Self or I am thus theology and finally the dedication to advance our understandings of Human Behaviour and 
Human Resilience by the study of Medicine and Science, hence Neurology or otherwise Psychology, Psychiatry and the Sciences alike including the Arts, Philosophy and Theology in knowing the full value of the Creativity of the Mind and the Higher Intuitive Mind to be as a Service Unit and Faculty gathered under Servicing the needs of others'. To overcome obstacles when they present themselves one by one, bettering ourselves in time gaining resilience and continuing to grow from adversity whilst learning from challenges presenting themselves in our lives, to learn through sharing, application, studious approach and discernment meanwhile industriously applying what we have learned to our surroundings at the same time utilising creativity, imagination and belief in ourselves and our lives contained within the collective consciousness and sub-conscious perceptions of the inner and outer schools of thought.

Whilst also having Hope, Faith and Love for our fellow man or woman including ourselves to better ourselves and one another throughout Humanity one by one and growing unitedly therefore evolving to a higher state of global consciousness unheard of before. In conceptualizing that the limitations placed in our lives are but boundaries of limiting factors regarding safety and a position of Central Location of commonality towards the outer spheres of consciousness through continually furthering our aims by moving from such a position of central location, outwards, towards further steps in our lives being achieved one at a time from such boundaries placed, but not set in stone, in therefore acquiring further learning's, experience and growth by continually testing such limitations placed and moving outwards ever outwards one step at a time whilst continually moving inwards towards the central location in a state of continual flux as if like a tidal force.

Meanwhile experimenting upon Human Nature in our own Quantum Servicing and Quantum Machinery to then achieve Human Resilience and overcome any obstacle by continually altering parts and components of experimental methodology and processes one faucet at a time therefore obtaining purification of the experimentation upon ourselves to overcome obstacles that present themselves one at a time increasing neural tissue and Brain Density. In knowing the process of delineation of component parts of processes and methodology can bring the self-experimentation to a purified state of awareness and level of conscious perception unknown before, in knowing limitation is only limiting factors and one Quanta of limiting factors may move the entire spectrum of conscious thought and Universe. In that one Quanta or Singular Drop of Consciousness contains the Whole Universal Collective Consciousness or Ocean of Collective Consciousness and the Ocean of Collective Consciousness or Universal Collective Consciousness is contained within the individual singular Drop or Quanta and so forth one singular Drop or Quanta can move the entire Universe or Ocean whether it is the Universal Collective Consciousness of Living Universal Beings and/or Entities or otherwise the Entire Ocean of Source of Collective Consciousness and the Source of all things.
In knowing that one individual Quanta of Consciousness or Drop of Source is an Infinite Spark of Infinite Potential within the Infinite Ocean of Consciousness containing the entire Memory of the Universal Collective Source from beginning to end as one and one singular drop of Source or Consciousness is able to tap into this Universal knowledge, power, Greater Source of Infinite Potential and Infinite Spark of Infinite Potential, at will, simply by moving one individual singular Quanta or Drop of Universal Source or Quanta of Thought Consciousness with intention that such desires be made manifest. In that Proof can be viewed literally by the acts of such Greats as Buddha, Jesus, Mohammed, Krishna and many more whom obtained Greatness by being 'that' singularity that became a Global Phenomenon encompassing the Whole Earth and changing how we ourselves govern our lives, how we view other's and how we may ease the suffering of those around us meanwhile raising our own elevation into the heavens or into Greatness otherwise into the Light. To view the Collective as being all that which is contained within the individual and the individual as all that there is contained within the collective none isolating another.

To value the collective consciousness and sub-conscious thoughts of a collective environment to view the world with Hope that regardless of whatever circumstances are in our lives individually or collectively that we are all supported through an elemental desire of Hope and the collective principles placed upon Male and Female roles, Religious Archetypes or otherwise Socio-Economic Wellbeing. And in regards to issues that may arise, and, as such issues arise from the sub-conscious realm to manifest only to deal with the issues it desires to deal with and impart a kernel of knowledge or spiritual wisdom, give you rewards and abundance in Wisdom, Knowledge and Wealth to then receive abundantly to give abundantly and overcome any obstacle or adversity by gathering under the value of having and holding onto Hope in order to give and receive freely without desire for need nor want for anything in return, in that it is shown that water freezes at different Rates, Densities and Vibrational Frequencies through the empowerment of Hope and so as such this is not to be disregarded.

That Hope is of much concern to the Peer Support Communities and therefore regard Hope as Highly valued and prized above all things as being an endearing desire to obtain a gift, prize, objective, attainment of goal, achievement of aims or otherwise Hope for a brighter tomorrow. In that we may become as Beacons of light and viewing the World as differentiating between diverse Human Behavioural Traits rather than Human addictions, Fantastic viewpoints of the Universe and the Nature of the Universal Laws at play, thereof, contained within the Collective Psyches and how we individually view ourselves in society whilst bringing all conceived principles into harmony and unison, unified under the banner of Health as paramount, Mental Health, Wellness and overall Wellbeing as crucial and essential in this day and age in Humanities existence. 
And finally it is of much concern to the Philosophical and Theosophical Societies in regards to the nature of Human Psyche regarding Free-will or cognitive volition in that such an order of conscious realities are the resulting efforts of the undermining of the Human Species relating to the Free-Will of all conscious Human Collective Psyches.

To regard its own Free-Will as a means to do as such individuals like and as to whether through a means of collective consciousness or otherwise individuation we can, Humanity as a whole, sustain global peace or a global collective Psyche resulting in a unified collective global consciousness. Not simply primarily the individual individuation and evolution of the Human species and arguably so that the Human brain and the acquisition of a Neo-Cortex otherwise known as the Cerebrum is the resulting factor relating to the Free-Willed Higher order thinking and processing of the Human Species and therefore is a dilemma concerning such Higher Thinking Poets, Metaphysicists, Philosophers and Neurologists. But knowing the value of Free-Will meanwhile building valuable brain tissue in further evolutionary states of consciousness will bring to bear an overall unification of the collective psyche, the self and the Ego into greater unison and harmony.

And by continuing in our healthy pursuits and aiming towards total wellbeing and wellness will improve our lives exponentially whilst remaining as a Light of Hope guiding others to wellness and wellbeing in unification of Mind, Body, Soul, Spirit, Unified Collective Principles and Unified Collective Archetypes in NonDuality as one increasing neural-tissue, neural-resilience and neuroplasticity in acquisition of further establishments of brain development. By furthering our own understandings of the nature regarding the Human Brain and Brain Chemistry by Assisted Human Advances and Studies invested into Medicine, Studies invested into the Collective Psyche and Collective Consciousness due to such Advances in Psychology and the study of the nature of the Universal Laws and principles abounding in Science. Meanwhile in Co-creation and Creation of the Arts via the Creativity of the Mind to quantum entanglement by quantum mechanics utilising quantum entanglement and coupling a mindful and loving heart, a well, unified and healthy brain or mind, a unified soul and collective sub-consciousness, a collective spirit and infinite spark of infinite potential to bear in this modern day age and the realities created by the individual individuation of society.

To combat the everlasting appeal for humanity to degrade itself to then eating of its own self and flesh to survive as an entity governed around illness, ill-health, mental instability and mental disorder, unrest, war, quarrels, contentions, qualms, squabbling's and the governing principles of brutality and violent behaviour.

And furthermore opposing a fear minded society that sophisticates itself around the complexities of the individual individuation of society, each individual reflecting each their own shadow selves towards another, which reflects the nature of war and contention amongst peoples bringing people into opposition with each other. And as long as this is so, the Global Environment is sick and unwell and needs to be serviced from a position of Health, Neutrality, Non-Judgement, Compassion, Empathy, Commonality, Sharing of our lives and eyes of recovery Story-telling, Being Engaged and /or in a Collective Connectivity, Medicine, Mental Health, Overall Wellbeing, Wellness, NonDualism, Resourcefulness, Abundance without neediness, Unconditionally Loving without Co-dependence, Faithful without Force of imbalance and Division between peoples whilst supporting others holistically.

Meanwhile towards positions of one of a New Hope in having and holding onto Hope at all times to see our lives and our patients lives improvements regardless of each our own individual circumstances or otherwise their own individual circumstances nor environmental changes or shifts. 'Seeking to always Better Ourselves' and reflecting such upon our clients, improving in our own understandings of only truth whilst encouraging other's to improve in their own understandings of such truths' regardless of whether such individuals find the Absolute truth or just a Kernel. Learning from our failings or short sightedness at times through hindsight therefore balancing polarities, meanwhile gently guiding others to view the Light and Dark in all circumstances and furthermore out ruling narrow-mindedness in our own mind meanwhile always seeking the Truth in all things but also giving room for an individual to share and express their needs, views and/or desires as such individuals desire to do so without infringing upon any boundaries that such individuals set.

Whilst we ourselves the Peer Support Community set our own boundaries and they will not be crossed only in retaliation to an act of war or violence by a strike upon the Heads of State as being the Ambassadors, Representatives, Leaders, Role-Models, Mental Health community and resounding Mental Health Leaders and Pioneers or waged acquisition of resources upon our lands and our Governing Bodies each all such Peer Support Members individually govern their entire bodily nervous systems as one and will be conducted by ourselves as 'Dialogue and a War of Words'.

\section{References}

1. North eastern University (2017) Traumatic Brain Injury Resource for Survivors and Caregivers.

2. Kinser PA (2000) Brain Structures and their functions.

3. Rohm R (2017) What is the Cerebrum? - Definition, Functions \& Location.

4. Pietrangelo A (2016) Brain Anatomy. Health line, College of Medicine, University of Illinois, Chicago, USA.

5. (2017) Parietal Lobe. The Spinal Cord Injury.

6. Vanderah TW, DJ Gould, Noltes (2017) Know your brain: Diencephalon. Neuroscientifically Challenged. 
7. Avery Martin (2018) What Is Arbor Vitae in Biology?. Hearst Seattle Media, LLC.

8. Robert MS MD (2015) An Overview of the Hypothalamus. Endocrine Web.

9. The Pituitary Foundation (2017) What is the pituitary gland?. The Editorial team Pituitary Foundation.

10. Crystalinks (2015) Third Eye - Pineal Gland. Crystalinks Editorial Team.
11. (2017) Hippocampus. The Brain Made Simple.

12. (2017) Amygdala. The Brain Made Simple.

13. R Bailey (2017) Cingulate Gyrus and the Limbic System. Thought Co.

14. Healthline Medical Team (2015) Cerebellum. Healthline Editorial Team.

\section{Your next submission with Juniper Publishers} will reach you the below assets

- Quality Editorial service

- Swift Peer Review

- Reprints availability

- E-prints Service

- Manuscript Podcast for convenient understanding

- Global attainment for your research

- Manuscript accessibility in different formats ( Pdf, E-pub, Full Text, Audio)

- Unceasing customer service

Track the below URL for one-step submission https://juniperpublishers.com/online-submission.php 